“ (C) 2019 IEEE. Personal use of this material is permitted. Permission from IEEE must be obtained for all other uses, in any current or future media, including

reprinting/republishing this material for advertising or promotional purposes, creating new collective works, for resale or redistribution to servers or lists, or reuse of any copyrighted component of this work in other works." 


\title{
Robust Design Optimization of a High-temperature Superconducting Linear Synchronous Motor Based on Taguchi Method
}

\author{
Gang Lei, Chengcheng Liu, Yanbin Li, Dezhi Chen, Youguang Guo, \\ and Jianguo Zhu Senior Member, IEEE
}

\begin{abstract}
This paper investigates the efficient robust design and optimization of a high-temperature superconducting (HTS) linear synchronous motor by using the Taguchi parameter design approach. The manufacturing tolerances of the HTS magnets, primary iron core and the air gap are considered in the robust design to ensure that the optimal design is less sensitive to these uncertainties. To overcome the disadvantages of the conventional Taguchi parameter design approach, a sequential Taguchi robust optimization method is presented for improvement of the motor performance and manufacturing quality. The proposed method is efficient because it holds the advantages of both Taguchi method and sequential optimization strategy. It can significantly increase the average thrust and decrease the thrust ripple of the investigated HTS linear synchronous motor.
\end{abstract}

Index Terms - High-temperature superconducting linear synchronous motor, manufacturing tolerances, optimization method, robust design, Taguchi method.

\section{INTRODUCTION}

$\mathbf{H}$ IGH temperature superconducting (HTS) technology has been attracted much attention worldwide in recent years due to its promising potential applications in power systems and transportation. For the application in transportation, it can be used to design HTS linear motors to provide linear motion drive for magnetic levitation trains [1-5]. An HTS linear motor with the integration of a magnetic suspension subsystem is able to provide merits of HTS magnetic suspension and linear motion drive. Therefore, HTS linear motor is promising for the maglev applications [6-11].

To provide excellent drive performance for such an expensive transportation system, HTS linear motors should be

\footnotetext{
Manuscript receipt and acceptance dates will be inserted here. This work was supported in part by research project (No. 19A470005) of the department of education of Henan Province, project (No. K2018YY016) of Zhongyuan University of Technology, and State Key Laboratory of Reliability and Intelligence of Electrical Equipment (No. EERIKF2018005), Hebei University of Technology.

G. Lei and Y. Guo are with the School of Electrical and Data Engineering, University of Technology Sydney, Australia (email: gang.lei@uts.edu.au).

C. Liu is with the State Key Laboratory of Reliability and Intelligence of Electrical Equipment, Hebei University of Technology Tianjin, China (email: 2016020@hebut.edu.cn).

$\mathrm{Y} . \mathrm{Li}$ is with the School of Electric and Information Engineering, Zhongyuan University of Technology, Zhengzhou, China

D. Chen is with the School of Electrical and Electronic Engineering, Huazhong University of Science and Technology, Wuhan, China.

$\mathrm{J}$. Zhu is with the School of Electrical and Information Engineering, The University of Sydney, Australia.
}

properly designed and optimized before applications. There are several popular design objectives, such as maximizing the average thrust and efficiency and minimizing the thrust ripple of the HTS motors. To achieve these objectives, several design parameters of the motor like dimensions should be optimized by using some design optimization methods, such as intelligent optimization algorithms, multilevel and multi-objective optimization methods [12-16].

On the other hand, there are many unavoidable variations for the design parameters in the production of HTS linear motors due to the practical manufacturing tolerances and material diversities. For example, the length of the air gap of a practical HTS linear motor and other electrical machines after manufacturing cannot be exactly equal to the optimally designed value $[17,18]$. Moreover, there are some uncertainties for the remanence of the HTS magnets. These variations will significantly affect the performance and quality of the manufactured HTS motors. Therefore, besides the consideration of motor performance, the manufacturing quality (against the manufacturing variations) of the HTS motors should be investigated in the design stage. This issue is very important as safety and comfortableness are two crucial requirements for transportation. To address this issue, robust design optimization should be investigated. To the best of the knowledge, this issue has not yet been investigated for the HTS linear motors.

This paper aims to develop a robust design optimization method for a single-sided HTS linear synchronous motor (HTSLSM) and present a new robust design optimization method to solve it based on the conventional Taguchi parameter design approach.

\section{HTSLSM AND MODELS}

Fig. 1 illustrates two models for a single-sided HTSLSM developed in our previous work. As shown in Fig. 1(a), there are 24 YBCO HTS magnets on the secondary and concentrated windings on the primary of this motor. The secondary is installed in a cryogenic vessel to ensure the superconductivity. Regarding the magnetic poles, six alternating poles are formed in the direction of movement based on the arrangement of the HTS magnets on the secondary. Fig. 1(b) shows an experimental setup for a prototype of this motor [19,20]. Fig. 2 illustrates the finite element model (FEM) and main design parameters for the performance evaluation of this motor. 


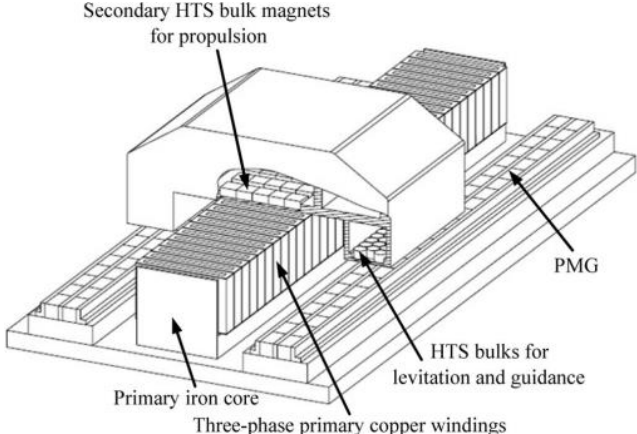

(a)

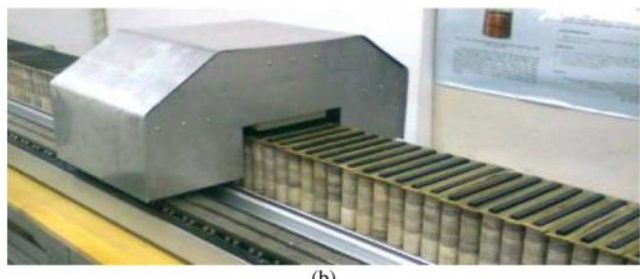

Fig. 1. A model (a) and a prototype (b) for the HTSLSM.

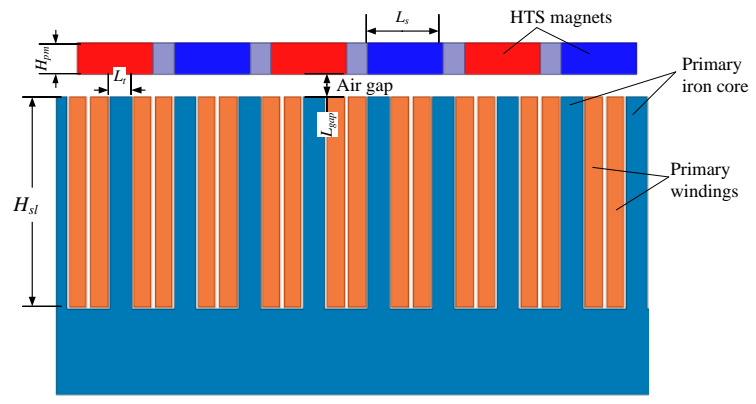

Fig. 2. FEM and design parameters of the HTSLSM

TABLE I

DESIGN PARAMETERS AND RANGES

\begin{tabular}{|c|c|c|c|c|}
\hline Par. & Unit & Initial & Min & Max \\
\hline$L_{g a p}$ & $\mathrm{~mm}$ & 10.5 & 9 & 12 \\
\hline$H_{p m}$ & $\mathrm{~mm}$ & 15 & 13 & 16 \\
\hline$H_{s l}$ & $\mathrm{~mm}$ & 100 & 90 & 105 \\
\hline$L_{s}$ & $\mathrm{~mm}$ & 35 & 34 & 40 \\
\hline$L_{t}$ & $\mathrm{~mm}$ & 10 & 8 & 11 \\
\hline
\end{tabular}

For the design optimization of this motor, five parameters as shown in Fig. 2 will be considered to maximize the average thrust and minimize the thrust ripple based on the FEM. The accuracy of the FEM for the analysis of this motor (for a specific air gap and frequency) has been verified by experimental results in terms of different aspects in our previous work [20, 21]. For example, the measured and calculated amplitudes of the back electromotive force are 10.9 and $10.58 \mathrm{~V}$, respectively. The relative error of them is only $2.94 \%$. Hence, the following optimal results obtained based on FEM are reliable.

Table I lists the initial values and ranges of the design parameters. As shown, design parameters include the dimensions of the HTS magnets $\left(H_{p m} \& L_{s}\right)$, the length of the air gap $\left(L_{\text {gap }}\right)$, and the dimensions of the primary tooth-slot $\left(H_{s l} \& L_{t}\right)$. For the manufacturing quality of this motor, it highly depends on the manufacturing tolerances of the air gap and HTS magnets. These parameters are crucial for the motor performance based on our previous design experience.

\section{Robust Design BASED ON TAGUChI Method}

In general, for the robust design of permanent motors, there are two popular optimization methods, Taguchi parameter design and design for six-sigma methods [17]. Taguchi method will be considered for the robust design of this HTSLSM due to its high efficiency (less computation cost). To implement this method, an orthogonal array consisting of an inner array (designed for control factors) and an outer array (designed for noise factors which are hard or expensive to control) will be required to implement the simulation of motor performance [21-24]. Tables II \& III list the five control factors and four noise factors as well as their design levels. As shown, there are four levels for each control factor and 2 levels for each noise factor.

TABLE II

LEVELS OF CONTROL FACTORS

\begin{tabular}{|c|c|c|c|c|c|}
\hline Control & \multirow{2}{*}{$\begin{array}{c}\text { Factor } \\
\text { Unit }\end{array}$} & \multicolumn{5}{|c|}{ Levels } \\
\cline { 3 - 6 } & 1 & 2 & 3 & 4 \\
\hline$L_{g a p}$ & $\mathrm{~mm}$ & 10 & 10.25 & 10.5 & 10.75 \\
\hline$H_{p m}$ & $\mathrm{~mm}$ & 14 & 14.5 & 15 & 15.5 \\
\hline$H_{s l}$ & $\mathrm{~mm}$ & 98 & 99 & 100 & 101 \\
\hline$L_{s}$ & $\mathrm{~mm}$ & 34 & 34.5 & 35 & 35.5 \\
\hline$L_{t}$ & $\mathrm{~mm}$ & 9 & 9.5 & 10 & 10.5 \\
\hline
\end{tabular}

TABLE III

LEVELS OF NOISE FACTORS

\begin{tabular}{|c|c|c|c|}
\hline \multirow{2}{*}{$\begin{array}{c}\text { Noise } \\
\text { Factor }\end{array}$} & \multirow{2}{*}{ Unit } & \multicolumn{2}{|c|}{ Levels } \\
\cline { 3 - 4 } & & 1 & 2 \\
\hline$\Delta B_{r}$ & $\mathrm{~T}$ & -0.015 & +0.015 \\
\hline$\Delta L_{g a p}$ & $\mathrm{~mm}$ & -0.1 & +0.1 \\
\hline$\Delta H_{p m}$ & $\mathrm{~mm}$ & -0.1 & +0.1 \\
\hline$\Delta L_{s}$ & $\mathrm{~mm}$ & -0.1 & +0.1 \\
\hline
\end{tabular}

Table IV lists the orthogonal array generated from these factors. As shown, it has 16 rows to form the inner array. These rows are defined by those control factors. For the outer array, it has 8 columns, and they are listed as 1111,1112 , $1221,1222,2121,2122,2211$ and 2212 in the table. 1 or 2 represents the level of the noise factor. For example, the first 1 in the 1221 means the remanence $\left(B_{r}\right)$ of HTS magnets is $0.485 \mathrm{~T}$. It is calculated by $0.5-0.015$, where $0.5 \mathrm{~T}$ is the initial design value. Therefore, 128 (16×8) combinations (FEM samples) will be required to simulate the performance for this motor. After the simulation in Maxwell, the average thrust and thrust ripple of these samples can be obtained. To determine the best values of control factors, an objective function is defined as follows

$$
y(i, j)=\frac{T_{\text {ave_initial }}}{T_{\text {ave }}(i, j)}+\frac{T_{\text {rip }}(i, j)}{T_{\text {rip_initial }}},
$$

where $T_{\text {ave }}$ and $T_{\text {rip }}$ are the average thrust and thrust ripple, respectively, subscript initial means the corresponding performance parameters of the initial design as listed in Table I, $i$ $(1,2, \ldots, 16)$ and $j(1,2, \ldots, 8)$ are the of experiment numbers of the control and noise factors, respectively. Table IV lists the calculated objective values for these 128 simulations.

According to the Taguchi parameter design, the signal/noise $(\mathrm{S} / \mathrm{N})$ ratio can be employed to identify the best combination of control factor values. 
TABLE IV

THE ORTHOGONAL ARRAY AND OBJECTIVE VALUES FOR THE HTSLSM

\begin{tabular}{|c|c|c|c|c|c|c|c|c|c|c|c|c|c|}
\hline & \multicolumn{9}{|c|}{ Control factors } & \multicolumn{10}{|c|}{ Noise factors } \\
\hline No & $\mathbf{1}$ & $\mathbf{2}$ & $\mathbf{3}$ & $\mathbf{4}$ & $\mathbf{5}$ & $\mathbf{1 1 1 1}$ & $\mathbf{1 1 1 2}$ & $\mathbf{1 2 2 1}$ & $\mathbf{1 2 2 2}$ & $\mathbf{2 1 2 1}$ & $\mathbf{2 1 2 2}$ & $\mathbf{2 2 1 1}$ & $\mathbf{2 2 1 2}$ \\
\hline $\mathbf{1}$ & 1 & 1 & 1 & 1 & 1 & 1.741 & 1.725 & 1.824 & 1.808 & 1.694 & 1.678 & 1.772 & 1.755 \\
\hline $\mathbf{2}$ & 1 & 2 & 2 & 2 & 2 & 1.797 & 1.819 & 1.815 & 1.832 & 1.752 & 1.777 & 1.801 & 1.816 \\
\hline $\mathbf{3}$ & 1 & 3 & 3 & 3 & 3 & 1.699 & 1.691 & 1.710 & 1.701 & 1.659 & 1.651 & 1.692 & 1.683 \\
\hline $\mathbf{4}$ & 1 & 4 & 4 & 4 & 4 & 1.587 & 1.619 & 1.595 & 1.616 & 1.547 & 1.564 & 1.576 & 1.600 \\
\hline $\mathbf{5}$ & 2 & 1 & 2 & 3 & 4 & 1.659 & 1.650 & 1.673 & 1.664 & 1.621 & 1.613 & 1.650 & 1.641 \\
\hline $\mathbf{6}$ & 2 & 2 & 1 & 4 & 3 & 1.708 & 1.753 & 1.719 & 1.766 & 1.668 & 1.701 & 1.698 & 1.729 \\
\hline $\mathbf{7}$ & 2 & 3 & 4 & 1 & 2 & 1.717 & 1.704 & 1.852 & 1.839 & 1.664 & 1.652 & 1.857 & 1.844 \\
\hline $\mathbf{8}$ & 2 & 4 & 3 & 2 & 1 & 1.867 & 1.881 & 1.894 & 1.892 & 1.813 & 1.834 & 1.887 & 1.881 \\
\hline $\mathbf{9}$ & 3 & 1 & 3 & 4 & 2 & 1.883 & 1.910 & 1.896 & 1.929 & 1.842 & 1.870 & 1.877 & 1.905 \\
\hline $\mathbf{1 0}$ & 3 & 2 & 4 & 3 & 1 & 1.994 & 1.978 & 2.005 & 1.989 & 1.949 & 1.934 & 1.991 & 1.975 \\
\hline $\mathbf{1 1}$ & 3 & 3 & 1 & 2 & 4 & 1.636 & 1.641 & 1.667 & 1.654 & 1.604 & 1.602 & 1.643 & 1.634 \\
\hline $\mathbf{1 2}$ & 3 & 4 & 2 & 1 & 3 & 1.703 & 1.692 & 1.861 & 1.850 & 1.692 & 1.682 & 1.855 & 1.844 \\
\hline $\mathbf{1 3}$ & 4 & 1 & 4 & 2 & 3 & 1.873 & 1.872 & 1.900 & 1.888 & 1.839 & 1.832 & 1.881 & 1.868 \\
\hline $\mathbf{1 4}$ & 4 & 2 & 3 & 1 & 4 & 1.679 & 1.668 & 1.757 & 1.746 & 1.668 & 1.658 & 1.691 & 1.679 \\
\hline $\mathbf{1 5}$ & 4 & 3 & 2 & 4 & 1 & 1.922 & 1.948 & 1.932 & 1.966 & 1.878 & 1.903 & 1.920 & 1.961 \\
\hline $\mathbf{1 6}$ & 4 & 4 & 1 & 3 & 2 & 1.811 & 1.800 & 1.819 & 1.807 & 1.768 & 1.757 & 1.806 & 1.794 \\
\hline
\end{tabular}

There are two main steps for the calculation of $\mathrm{S} / \mathrm{N}$ ratio. First, compute the $\mathrm{S} / \mathrm{N}$ ratio $(\mathrm{dB})$ for each row of the inner array. As the design target is the smaller the better, the calculation equation is

$$
S N(i)=-10 \times \lg \left[\frac{1}{8} \times \sum_{j=1}^{8} y^{2}(i, j)\right] .
$$

Table $\mathrm{V}$ lists the calculated $\mathrm{S} / \mathrm{N}$ ratio for each row of the inner array or the number of the simulation for the control factors. Second, calculate the average $\mathrm{S} / \mathrm{N}$ ratio for all levels of control factors based on the obtained $\mathrm{S} / \mathrm{N}$ ratios given in Table $\mathrm{V}$. For example, the average $\mathrm{S} / \mathrm{N}$ ratio for the third level of the control factor $L_{S}$ can be computed as follows.

$$
R\left(L_{s}, 3\right)=\frac{S N(3)+S N(5)+S N(10)+S N(16)}{4}=-4.97 \mathrm{~dB},
$$

the numbers $3,5,10$ and 16 can be found from the orthogonal array Tables V. Table VI tabulates the calculated average S/N ratios for all factors.

TABLE V

S/N RATIO FOR THE INNER ARRAY

\begin{tabular}{|c|c|c|c|}
\hline No & S/N ratio & No & S/N ratio \\
\hline 1 & -4.86 & 9 & -5.53 \\
\hline 2 & -5.11 & 10 & -5.92 \\
\hline 3 & -4.54 & 11 & -4.27 \\
\hline 4 & -4.02 & 12 & -4.98 \\
\hline 5 & -4.33 & 13 & -5.43 \\
\hline 6 & -4.70 & 14 & -4.58 \\
\hline 7 & -4.95 & 15 & -5.71 \\
\hline 8 & -5.43 & 16 & -5.08 \\
\hline
\end{tabular}

TABLE VI

\begin{tabular}{|c|c|c|c|c|c|}
\hline Factor & Level & $\mathrm{S} / \mathrm{N}$ ratio & Factor & Level & $\mathrm{S} / \mathrm{N}$ ratio \\
\hline \multirow{4}{*}{$L_{g a p}$} & 1 & -4.63 & \multirow{2}{*}{$H_{s l}$} & 3 & -5.02 \\
\hline & 2 & -4.85 & & 4 & -5.08 \\
\hline & 3 & -5.17 & \multirow{4}{*}{$L_{s}$} & 1 & -4.84 \\
\hline & 4 & -5.20 & & 2 & -5.06 \\
\hline \multirow{4}{*}{$H_{p m}$} & 1 & -5.04 & & 3 & -4.97 \\
\hline & 2 & -5.08 & & 4 & -4.99 \\
\hline & 3 & -4.87 & \multirow{4}{*}{$L_{t}$} & 1 & -5.48 \\
\hline & 4 & -4.88 & & 2 & -5.17 \\
\hline \multirow{2}{*}{$H_{s l}$} & 1 & -4.73 & & 3 & -4.91 \\
\hline & 2 & -5.03 & & 4 & -4.30 \\
\hline
\end{tabular}

AVERAGE S/N RATIO FOR EACH LEVEL OF CONTROL FACTORS
Fig. 3 shows the average $\mathrm{S} / \mathrm{N}$ ratios for all levels of each control factor. As the design target is the smaller the better, the best level of each factor is the one that has the highest $\mathrm{S} / \mathrm{N}$ ratio [23,24]. Therefore, levels $1,3,1,1$, and 4 are the best for the five control factors, respectively. For the HTSLSM with this optimal design, the average thrust is $419.2 \mathrm{~N}$ and the thrust ripple is $13.72 \%$, which are better than those of the initial design (387.3 $\mathrm{N}$ and $22.68 \%$ ). However, the improvement of the average thrust is not significant.

Meanwhile, these improvements depend on the levels defined in Table II. These levels are normally selected from design experience, and they form a small subspace compared with the initial big design space. How to efficiently identify this small subspace is a disadvantage for the conventional Taguchi parameter design approach. To overcome the above two problems, a sequential Taguchi robust optimization method (STROM) is presented in the next section.

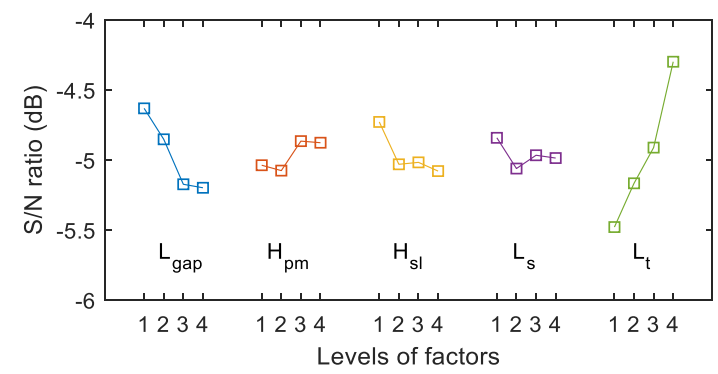

Fig. 3. Illustration of $\mathrm{S} / \mathrm{N}$ ratios for all factors

\section{Sequential Taguchi Robust Optimization Method}

Fig. 4 illustrates the flowchart of the proposed STROM. There are four main steps.

Step 1: Define the objective function, design parameters and their ranges (or the initial design space) for the HTSLSM.

Step 2: For the initial design space, select a level number for each control factor, implement the conventional Taguchi 
parameter design to identify the best combination of the control factor values.

Step 3: Compute the motor performance with the obtained design and compare it with the last objective. If the relative error between them is less than $\varepsilon$ (a positive value like 1\%), finish the optimization process and output the obtained optimal design. Otherwise, go to the next step and re-implement the Taguchi parameter design process.

Step 4: Reduce the design space of the control factors by using the optimal design. The space reduction method is defined as follows. Assume the initial design space of a control factor is $[a, b]$, and there are four levels with a step size $d$. If the optimal value of this factor is $x_{o}$, then the next four levels will be

$$
\left\{\begin{array}{cc}
{[a, a+d, a+2 d, a+3 d],} & x_{o}-3 d / 2<a \\
{[b-3 d, b-2 d, b-d, b],} & x_{o}+3 d / 2>b \\
{\left[x_{o}-3 d / 2, x_{o}-d / 2, x_{o}+d / 2, x_{o}+3 d / 2\right],} & \text { others }
\end{array}\right.
$$

If there are five levels for each control factor, the next five levels will be $\left[x_{o}-2 d, x_{o}-d, x_{o}, x_{o}+d, x_{o}+2 d\right]$. A similar method applies if the first and last levels are out of the design ranges. As shown, the design space can be halved by using this reduction strategy.

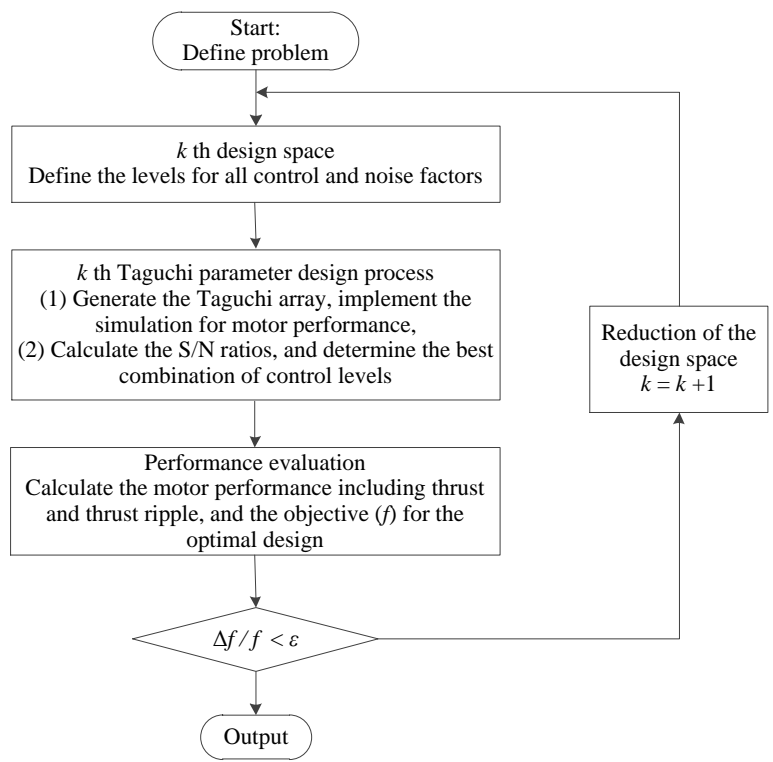

Fig. 4. Flowchart of the sequential Taguchi robust optimization method

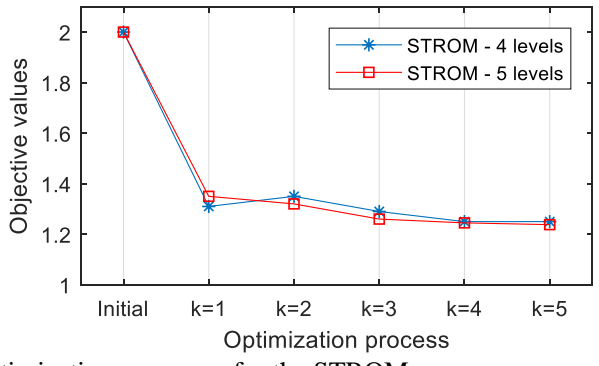

Fig. 5. Optimization processes for the STROM

To illustrate the effectiveness of the proposed method, Fig. 5 shows the optimization process for this method with two dif- ferent levels (4 or 5) for the control factors. In the figure, STROM-4levels means four levels are defined for each control factor with the initial design space. As shown, only 5 traditional Taguchi parameter design processes are required for them if the $\varepsilon$ is $1 \%$. Two optimal designs are obtained based on the proposed STROM. Table VII lists the optimal values of the control factors and the corresponding motor performance. The following conclusions can be drawn from this table.

1) For the optimal design given by the STROM with 4 levels for each control factor, the average thrust is $566.0 \mathrm{~N}$ and thrust ripple is $12.97 \%$, the corresponding objective value is 1.26. The average thrust has been increased by $35.02 \%$ and $46.14 \%$ compared with those of the conventional Taguchi design and the initial design, respectively. The thrust ripple has been decreased by $5.47 \%$ and $42.81 \%$ compared with those of the conventional Taguchi design and the initial design, respectively. The objective value has been decreased by $17.65 \%$ and $37.0 \%$ compared with those of the conventional Taguchi design and the initial design, respectively. Therefore, the motor performance has been improved greatly.

2) For the optimal design given by the STROM with 5 levels for each control factor, the average thrust is $539.9 \mathrm{~N}$ and thrust ripple is $11.48 \%$, the corresponding objective value is 1.22. The objective value is the smallest one among the four designs listed in the table. The average thrust is lower than that of STROM with 4 levels, but the thrust ripple is smaller as well.

TABLE VII

PERFORMANCE COMPARISON

\begin{tabular}{|c|c|c|c|c|c|}
\hline Parameter & Unit & Initial & Taguchi & $\begin{array}{c}\text { STROM- } \\
\text { 4 levels }\end{array}$ & $\begin{array}{c}\text { STROM- } \\
\text { 5 levels }\end{array}$ \\
\hline$L_{g a p}$ & $\mathrm{~mm}$ & 10.5 & 10 & 9 & 9 \\
\hline$H_{p m}$ & $\mathrm{~mm}$ & 15 & 15 & 16 & 13.84 \\
\hline$H_{s l}$ & $\mathrm{~mm}$ & 100 & 98 & 90 & 90 \\
\hline$L_{s}$ & $\mathrm{~mm}$ & 35 & 34 & 37.81 & 38.03 \\
\hline$L_{t}$ & $\mathrm{~mm}$ & 10 & 10.5 & 11 & 11 \\
\hline Force & $\mathrm{N}$ & 387.3 & 419.2 & 566.0 & 539.9 \\
\hline Force ripple & $\%$ & 22.68 & 13.72 & 12.97 & 11.48 \\
\hline Objective & - & 2.00 & 1.53 & 1.26 & 1.22 \\
\hline FEM & - & - & 128 & 640 & 1000 \\
\hline
\end{tabular}

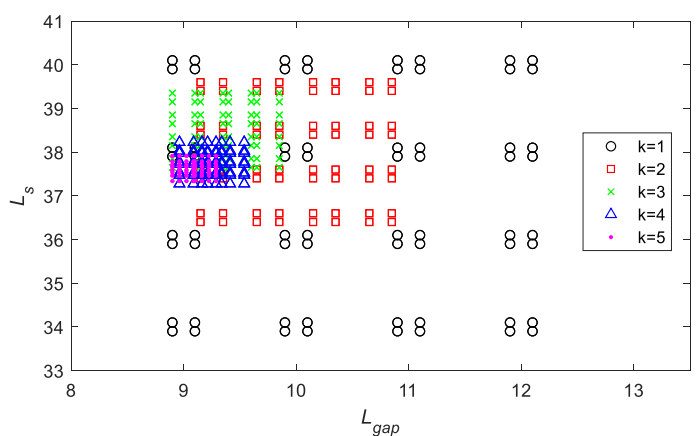

Fig. 6. Sampling process of two parameters in the STROM with 4 levels 


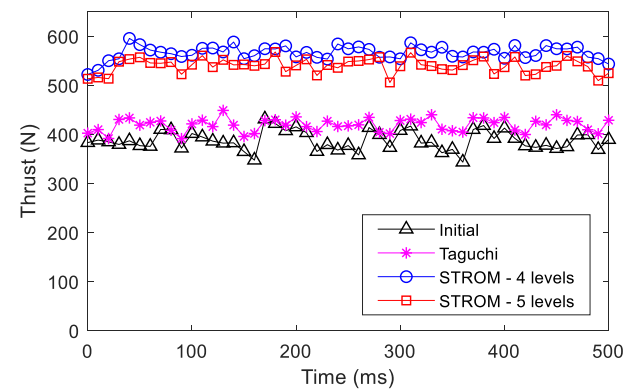

Fig. 7. Comparison of the thrust curves for different designs

3) Regarding the computation cost of FEM simulation, conventional Taguchi parameter design requires 128 FEM samples; the total simulation time is around 640 minutes with five minutes for each simulation. STROM with 4 and 5 as the control factor levels require 640 and 1000 FEM samples to meet the convergence criteria of the optimization method. STROM requires more computation cost compared with conventional Taguchi parameter design approach. However, all are acceptable. Fig. 6 illustrates the sampling process of two control factors $\left(L_{\text {gap }} \& L_{s}\right)$ for the STROM with four levels. As shown, the initial big design space (black circles) has been reduced to a small one (pink points) with five space reduction processes $(\mathrm{k}=5)$. Hence, the STROM is efficient.

4) A remark for the determination of levels for the control factors. Practically, equal and unequal step sizes can be used for the control factor levels, and they will affect the optimal values for the traditional Taguchi parameter design approach. However, they will not significantly affect the proposed STROM as the final step sizes after several optimization processes are very small. Thus, STROM is robust to the initial values and step sizes of the control factors.

\section{CONCLUSION}

This paper investigated the robust design of an HTSLSM with the consideration of manufacturing tolerances for several design parameters. To solve the disadvantages of the conventional Taguchi parameter design approach, a new robust optimization method, STROM, was developed. To illustrate the efficiency of the proposed method, two different levels (4 and 5) are investigated for the control factor levels. Through comparison, it can be found that the proposed method can significantly improve the motor performance (higher average thrust and lower thrust ripple) with less computation cost. The objectives of the optimal designs given by the STROM are less than $63 \%$ and $82.35 \%$ of those given by the initial design and conventional Taguchi design. The proposed STROM can be applied for the efficient robust design of other electrical machines with consideration of manufacturing variations.

\section{REFERENCES}

[1] T. Gong et al., "Electromagnetic Investigation of a High-Temperature Superconducting Linear Synchronous Motor for High-Speed Railway," IEEE Trans. Appl. Supercond., vol. 28, no. 3, pp. 1-5, April 2018.

[2] Z. Deng, J. Li, W. Zhang, Y. Gou, Y. Ren and J. Zheng, "HighTemperature Superconducting Magnetic Levitation Vehicles: Dynamic
Characteristics While Running on a Ring Test Line," IEEE Vehicular Technology Magazine, vol. 12, no. 3, pp. 95-102, Sept. 2017.

[3] Z. Deng et al., "A High-Temperature Superconducting MaglevEvacuated Tube Transport (HTS Maglev-ETT) Test System," IEEE Trans. Appl. Supercond., vol. 27, no. 6, Art no. 3602008, Sept. 2017.

[4] G. Ma et al., "Experiment and Simulation of REBCO Conductor Coils for an HTS Linear Synchronous Motor," IEEE Trans. Appl. Supercond., vol. 27, no. 4, pp. 1-5, June 2017.

[5] F. Martins, D. Dias, A. Ferreira and R. Andrade, "Project of a HTS Synchronous Machine Emulated by a Linear Motor," IEEE Trans. Appl. Supercond., vol. 25, no. 3, pp. 1-5, June 2015.

[6] Z. Deng et al., "A High-Temperature Superconducting Maglev Ring Test Line Developed in Chengdu, China," IEEE Trans. Appl. Supercond., vol. 26, no. 6, Art no. 3602408, Sept. 2016.

[7] C. Y. Lee et al., "Conceptual Design of Superconducting Linear Synchronous Motor for 600-km/h Wheel-Type Railway," IEEE Trans. Appl. Supercond., vol. 24, no. 3, pp. 1-4, June 2014.

[8] Z. H. Wu and J. X. Jin, "Characteristic Analysis of HTS Linear Synchronous Generators Designed With HTS Bulks and Tapes," IEEE Trans. Appl. Supercond., vol. 24, no. 5, pp. 1-5, Oct. 2014.

[9] W. Duan et al., "Experimental Study of Thrusts of a Cylindrical Linear Synchronous Motor With One or More YBCO Bulk Magnets as the Excitation System," IEEE Trans. Appl. Supercond., vol. 25, no. 1, pp. 1-6, 2015.

[10] S. J. Zheng et al., "Performance of a Small-Scale High Temperature Superconducting Linear Synchronous Motor Prototype," IEEE Trans. Appl. Supercond., vol. 22, no. 2, Art. 5200104, April 2012.

[11] J. Li, F. Yen, S. Zheng, S. Wang and J. Wang, "Normal Force Analysis on a High Temperature Superconducting Linear Synchronous Motor," IEEE Trans. Appl. Supercond., vol. 22, no. 3, Art. 5200304, June 2012.

[12] G. Lei, T. Wang, J. Zhu, et al., "System level design optimization method for electrical drive systems: deterministic approach," IEEE Trans. Ind. Electron., vol. 61, no. 12, pp. 6591-6602, 2014.

[13] Z. Xiang, X. Zhu, L. Quan, Y. Du, C. Zhang, D. Fan, "Multilevel design optimization and operation of a brushless double mechanical port fluxswitching permanent-magnet motor," IEEE Trans. Ind. Electron., vol. 63, no. 10, pp. 6042-6054, 2016.

[14] G. Lei, C. Liu, J. Zhu, and Y. Guo, "Techniques for multilevel design optimization of permanent magnet motors," IEEE Trans. Energy Convers., vol. 30, no. 4, pp. 1574-1584, 2015.

[15] Y. Wang, S. Niu and W. Fu, "Sensitivity analysis and optimal design of a dual mechanical port bidirectional flux-modulated machine," IEEE Trans. Ind. Electron., vol. 65, no. 1, pp. 211-220, 2018.

[16] X. Sun, B. Su, S. Wang, et al. "Performance analysis of suspension force and torque in an IBPMSM with V-shape PMs for flywheel batteries," IEEE Trans. Magn., vol. 54, no. 11, Art. no. 8105504, 2018.

[17] B. Ma, G. Lei, J. Zhu, Y. Guo and C. Liu, "Application-oriented robust design optimization method for batch production of permanent-magnet motors," IEEE Trans. Ind. Electron, vol. 65, no. 2, pp. 1728-1739, 2018.

[18] C. Liu, G. Lei, B. Ma, Y. Guo, and J. Zhu, "Robust design of a low-cost permanent magnet motor with soft magnetic composite cores considering the manufacturing process and tolerances," Energies, vol. 11, no. 8, Art. no. 2025, 2018.

[19] J. X. Jin, et al., "High-temperature superconducting linear synchronous motors integrated with HTS magnetic levitation components," IEEE Trans. Appl. Supercond., vol. 22, no. 5, Art. no. 5202617, 2012.

[20] J. X. Jin, et al., "Performance characteristics of an HTS linear synchronous motor with HTS bulk magnet secondary," IEEE Trans. Ind. Appl., vol. 47, no. 6, pp. 2469-2477, 2011.

[21] J. Song, F. Dong, J. Zhao, S. Lu, S. Dou and H. Wang, "Optimal design of permanent magnet linear synchronous motors based on Taguchi method," IET Electr. Power Appl., vol. 11, no. 1, pp. 41-48, 12017.

[22] F. Dong, J. Song, J. Zhao and J. Zhao, "Multi-objective design optimisation for PMSLM by FITM," IET Electr. Power Appl., vol. 12, no. 2, pp. 188-194, 22018.

[23] S. Lee, K. Kim, S. Cho, J. Jang, T. Lee and J. Hong, "Optimal design of interior permanent magnet synchronous motor considering the manufacturing tolerances using Taguchi robust design," IET Electr. Power Appl., vol. 8, no. 1, pp. 23-28, January 2014.

[24] K. S. Kim, K. T. Jung, J. M. Kim, J. P. Hong and S. I. Kim, "Taguchi robust optimum design for reducing the cogging torque of EPS motors considering magnetic unbalance caused by manufacturing tolerances of PM," IET Electr. Power Appl., vol. 10, no. 9, pp. 909-915, 2016. 